\title{
Strategic sizing of energy storage facilities in electricity markets
}

Nasrolahpour, Ehsan; Kazempour, Seyyedjalal; Zareipour, Hamidreza; Rosehart, William D.

Published in:

IEEE Transactions on Sustainable Energy

Link to article, DOI:

10.1109/TSTE.2016.2555289

Publication date:

2016

Document Version

Peer reviewed version

Link back to DTU Orbit

Citation (APA):

Nasrolahpour, E., Kazempour, S., Zareipour, H., \& Rosehart, W. D. (2016). Strategic sizing of energy storage facilities in electricity markets. IEEE Transactions on Sustainable Energy, 7(4), 1462-1472.

https://doi.org/10.1109/TSTE.2016.2555289

\section{General rights}

Copyright and moral rights for the publications made accessible in the public portal are retained by the authors and/or other copyright owners and it is a condition of accessing publications that users recognise and abide by the legal requirements associated with these rights.

- Users may download and print one copy of any publication from the public portal for the purpose of private study or research.

- You may not further distribute the material or use it for any profit-making activity or commercial gain

- You may freely distribute the URL identifying the publication in the public portal 


\title{
Strategic Sizing of Energy Storage Facilities in Electricity Markets
}

\author{
Ehsan Nasrolahpour, Student Member, IEEE, S. Jalal Kazempour, Member, IEEE, \\ Hamidreza Zareipour, Senior Member, IEEE, and William D. Rosehart, Senior Member, IEEE
}

\begin{abstract}
This paper proposes a model to determine the optima size of an energy storage facility from a strategic investor's perspective. This investor seeks to maximize its profit through making strategic planning, i.e., storage sizing, and strategic operational, i.e., offering and bidding, decisions. We consider the uncertainties associated with rival generators' offering strategies and future load levels in the proposed model. The strategic investment decisions include the sizes of charging device, discharging device and energy reservoir. The proposed model is a stochastic bi-level optimization problem; the planning and operation decisions are made in the upper-level, and market clearing is modeled in the lower-level under different operating scenarios. To make the proposed model computationally tractable, an iterative solution technique based on Benders' decomposition is implemented. This provides a master problem and a set of subproblems for each scenario. Each subproblem is recast as an Mathematical Programs with Equilibrium Constraints (MPEC). Numerical results based on real-life market data from Alberta's electricity market are provided.
\end{abstract}

Index Terms-Energy Storage, Planning, Bidding strategy, Benders' decomposition, Mathematical Programs with Equilibrium Constraints (MPEC).

\section{NOMENCLATURE}

\section{A. Indices}

$d \quad$ Index of load demands running from 1 to $N_{d}$ $g \quad$ Index of generators running from 1 to $N_{g}$ $l, m \quad$ Indices of Benders' iterations

$s \quad$ Index of energy storage systems running from 1 to $N_{s}$

$t \quad$ Index of hours running from 1 to $N_{t}$

$r \quad$ Index of scenarios running from 1 to $N_{r}$

$w \quad$ Index of weeks running from 1 to $N_{w}$

B. Parameters

$A C_{s}^{\text {dis }} \quad$ Annual capital cost of energy storage system $s$ for the storage discharge device, $(\$ / \mathrm{MW}-\mathrm{yr})$

$A C_{s}^{c h} \quad$ Annual capital cost of energy storage system $s$ for the storage charge device, (\$/MW-yr)

$A C_{s}^{r e s} \quad$ Annual capital cost of energy storage system $s$ for the storage reservoir, ( $\$ / \mathrm{MWh}-\mathrm{yr})$

$E_{s}^{i n i} \quad$ Initial value of stored energy of energy storage system $s,(\mathrm{MWh})$

E. Nasrolahpour, H. Zareipour, and W. D. Rosehart are with the Department of Electrical and Computer Engineering, Schulich School of Engineering, University of Calgary, Calgary, AB, Canada T2N 1N4 (e-mail: enasrola@ucalgary.ca; hzareipour@ucalgary.ca; rosehart@ucalgary.ca).

S. J. Kazempour is with the Technical University of Denmark, Kgs. Lyngby, Denmark (e-mail: seykaz@elektro.dtu.dk).
$K_{s}^{d i s, \max }$ Maximum capacity of available discharging device of energy storage system $s$, (MW)

$K_{s}^{c h, \max }$ Maximum capacity of available charging device of energy storage system $s$, (MW)

$K_{s}^{r e s, \max }$ Maximum capacity of available capacity reservoir of energy storage system $s$, (MWh)

$M C_{s}^{\text {dis }} \quad$ Marginal operating cost of energy storage system $s$ in the discharging mode, ( $\$ / \mathrm{MWh})$

$M C_{s}^{c h} \quad$ Marginal operating cost of energy storage system $s$ in the charging mode, (\$/MWh)

$M^{\text {ch }}, M^{\text {dis }}$ Large positive constants

$P_{g}^{\max } \quad$ Capacity of generator $g$, (MW)

$P_{d, w, t, r}^{\max } \quad$ Quantity bid of load demand $d$ at week $w$ at hour $t$ under scenario $r$, (MW)

$U_{d, w, t} \quad$ Price bid of load demand $d$ at week $w$ at hour $t$, (\$/MWh)

$\alpha^{\text {min }} \quad$ Large negative constant

$\beta_{g, w, t, r} \quad$ Offer price of generator $g$ at week $w$ at hour $t$ under scenario $r$, (\$/MWh)

$\eta_{s} \quad$ Efficiency of energy storage system $s$

$\epsilon \quad$ Convergence tolerance of Benders' algorithm

$\varphi_{r} \quad$ Probability of scenario $r$

C. Variables

$e_{s, w, t, r} \quad$ Energy stored in energy storage system $s$ at week $w$ at hour $t$ under scenario $r$, (MWh)

$g^{i n v} \quad$ Storage investment cost, (\$)

$g_{w, r}^{o p r} \quad$ Storage operation profit at week $w$ under scenario $r,(\$)$

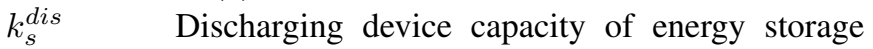
system $s,(\mathrm{MW})$

$k_{s}^{c h} \quad$ Charging device capacity of energy storage system $s,(\mathrm{MW})$

$k_{s}^{r e s} \quad$ Reservoir capacity of energy storage system $s$, (MWh)

$o_{s, w, t, r}^{d i s} \quad$ Price offer of energy storage system $s$ in the discharging mode at week $w$ at hour $t$ under scenario $r,(\$ / \mathrm{MWh})$

$o_{s, w, t, r}^{c h} \quad$ Price bid of energy storage system $s$ in the charging mode at week $w$ at hour $t$ under scenario $r,(\$ / \mathrm{MWh})$

$\bar{p}_{s, w, t, r}^{d i s} \quad$ Quantity offer of energy storage system $s$ in the discharging mode at week $w$ at hour $t$ under scenario $r$, (MW)

$\bar{p}_{s, w, t, r}^{c h} \quad$ Quantity bid of energy storage system $s$ in the charging mode at week $w$ at hour $t$ under scenario $r$, (MW) 
$p_{g, w, t, r} \quad$ Power produced by generator $g$ at week $w$ at hour $t$ under scenario $r$, (MW)

$p_{s, w, t, r}^{d i s} \quad$ Power produced by energy storage system $s$ in the discharging mode at week $w$ at hour $t$ under scenario $r,(\mathrm{MW})$

$p_{s, w, t, r}^{c h} \quad$ Power stored by energy storage system $s$ in the charging mode at week $w$ at hour $t$ under scenario $r,(\mathrm{MW})$

$p_{d, w, t, r} \quad$ Power consumed by load demand $d$ at week $w$ at hour $t$ under scenario $r$, (MW)

$u_{s, w, t, r}^{d i s} \quad$ Binary decision variable to indicate if energy storage system $s$ is in the discharging mode at week $w$ at hour $t$ under scenario $r$

$u_{s, w, t, r}^{c h} \quad$ Binary decision variable to indicate if energy storage system $s$ is in the charging mode at week $w$ at hour $t$ under scenario $r$

$u_{s, w, t, r}^{i d l} \quad$ Binary decision variable to indicate if energy storage system $s$ is in the idle mode at week $w$ at hour $t$ under scenario $r$

$\lambda_{w, t, r} \quad$ market-clearing price at week $w$ at hour $t$ under scenario $r,(\$ / \mathrm{MWh})$

$\mu$

Dual variables corresponding to the lower-level constraints. See Section (II) for details.

Note: When a symbol takes the hat sign, $\wedge$, it is converted from a variable in one problem to a fixed parameter in another problem.

\section{INTRODUCTION}

$\mathbf{W}$ ORLDWIDE investments in energy storage grew to over $\$ 675$ million by the end of 2014 , and is expected to reach $\$ 15$ billion by 2024 [1]. This is because despite the still high capital cost of bulk energy storage, it is seen as a viable solution to face some of the challenges of modern power systems, such as adding more flexibility, deferring investments, and peak load management [2]. Thus, several studies have focused on energy storage investment planning [3]-[13].

The existing literature on storage investment can generally be divided into two groups. The first group focuses on finding energy storage sizing in a vertically integrated power system where the storage is part of the system assets [3]-[9]. In the second group, the focus is on sizing for-profit merchant storage facilities in competitive markets [10]-[13]. The main distinction between the two groups is that in the former, energy storage is planned for improving power systems performance through load shifting, peak shaving, transmission congestion relief, ancillary service provision, renewable energy accommodation and etc. However in the latter, the facility is planned from an investor's point of view to compete in electricity markets through energy arbitrage. The latter is also the main focus of the present work.

More specifically, in the second group of energy storage investment planning literature [10]-[13], the fundamental assumption is often to assume the storage facility as a pricetaker facility. The actions and strategies of a price-taker market participant have a negligible impact on market prices. In these studies, the storage facility's operation is optimized under the assumption that the market prices are known in advance and are considered as exogenous parameters. While this assumption holds true for smaller sized facilities, it may not be necessarily the case when the size of the facility is relatively large. For example, while a small-scale battery facility could be easily seen as a price-taker unit in a market, a large-scale compressed air energy storage facility would certainly impact market prices. A larger facility, whose actions and operation strategies impact market prices, is referred to as a price-maker facility. We focus on a price-maker energy storage facility in the present paper.

In addition, in modeling competitive markets, the market is sometimes assumed to be perfect, i.e., market participants do not play strategically and submit their marginal cost/utility as their offer/bid prices (e.g., in [14]). However, in reality, electricity markets are often imperfect, and thus, game-theoretic complementarity models [15] are reported in the literature for modeling competition in electricity markets. The present work takes the imperfect market approach.

This paper proposes a complementarity model for sizing price-maker merchant energy storage facilities in imperfectly competitive electricity markets. The developed model has stemmed from an industry-university collaborative research project that focused on strategic energy storage sizing in Alberta's competitive market. Rocky Mountain Power Inc. [16], i.e., the industry partner, is considering to build a merchant energy storage in Alberta, Canada, whose main source of revenue is envisioned to be from energy arbitrage. Historical high price volatilities in Alberta's market allow for often large price differentials [17] that would make energy arbitrage an attractive option. Expanding the model to include other revenue streams (e.g., from participating in ancillary service markets) is beyond the scope of this paper and is part of the authors' future research. The facility modeled in this paper would act as a generation facility in discharging mode and as a load facility in charging mode. Modeling the operation of storage facilities that are owned by generation companies and are jointly operated alongside their other generation assets is not the focus of this work. In addition, the impact of storage investment and operation on short- or long-term emission displacements, and investments in other conventional technologies in the market are not within the scope of the present paper either.

Our work is different from [3]-[9] as we consider a merchant energy storage facility who participates in a competitive market to maximize its profit. Unlike [10]-[13], the storage facility is a price-maker in our proposed formulation and thus, the market prices are obtained as a function of the operation strategies of the storage facility and those of other market participants. Our work also differs from [14] in the sense that we consider an imperfect market model.

The problem of strategic investment planning in imperfectly competitive markets for price-maker conventional generators (e.g., [18]) or wind power producers (e.g., [19]) have been reported in the literature. In those studies, the decision variable is typically the generation capacity. However, in energy storage planning, the decision variables are charging, discharging and reservoir capacities. In addition, the cost of generating power in a conventional power plant depends on fuel prices; as long as the market price for electricity is more than the generation marginal costs, the operation is profitable. In the case of energy 
storage, however, the cost of charging and discharging are interdependent, and profitability depends on the differences between selling and buying prices. Our work differentiates itself from planning conventional generation facilities by modeling and including such fundamental differences that exist between a large price-maker energy storage facility and a conventional generation asset. We also include the uncertainties associated with future load and the operation offering strategy of conventional generation facilities by introducing a number of plausible scenarios. The advantage of doing so is that the results are more realistic than a deterministic solution since they are adapted to different potential realizations of the uncertain parameters. The challenge, however, is that it makes the proposed formulation very large for a real-life size case study. To overcome the potential computational troubles, we utilize an iterative solution method based on Benders' decomposition that makes the problem computationally tractable for a reasonable number of scenarios.

To summarize, the main contribution of this paper is to propose and solve a model for strategic sizing of merchant, price-maker energy storage facilities in imperfect electricity markets taking into account the uncertainties associated with the future load and conventional supply offers.

The rest of the paper is organized as follows. The proposed model and mathematical formulation are provided in Section II. The proposed solution technique is presented in Section III The numerical results are presented and discussed in Section IV The paper is concluded in Section V

\section{The Proposed Sizing Model}

Strategic energy storage planning is about determining the best values for charging, discharging and reservoir capacities to return the highest expected profit on investment. However, for a large merchant energy storage facility, its operation could affect market prices [9] and thus, its own profit. Furthermore, other market participants' strategies also impact market-clearing outcomes and hence, the profit of the storage facility. Thus, to find the optimal charging, discharging and reservoir capacity values, the operation of energy storage and the market-clearing process must be taken into account. Note that in this work, the storage facility is an independent market player who is neither part of a storage-wind nor storagesolar coalition, nor is part of the portfolio of a dominant generation company. While those are valid cases, modeling them is beyond the scope of the present work. The proposed sizing model is presented in (a.1)-(a.23), as follows:

$$
\begin{gathered}
\text { Max. } \quad-g^{i n v}+\sum_{w=1}^{N_{w}} \sum_{r=1}^{N_{r}} \varphi_{r} \cdot g_{w, r}^{o p r} \\
g^{i n v}=\sum_{s=1}^{N_{s}}\left[A C_{s}^{r e s} \cdot k_{s}^{r e s}+A C_{s}^{c h} \cdot k_{s}^{c h}+A C_{s}^{d i s} \cdot k_{s}^{d i s}\right] \\
g_{w, r}^{o p r}=\sum_{s=1}^{N_{s}} \sum_{t=1}^{N_{t}}\left[-\left(\lambda_{w, t, r}+M C_{s}^{c h}\right) \cdot p_{s, w, t, r}^{c h}\right. \\
\left.\quad+\left(\lambda_{w, t, r}-M C_{s}^{d i s}\right) \cdot p_{s, w, t, r}^{d i s}\right] \forall w, \forall r \\
0 \leq k_{s}^{c h} \leq K_{s}^{c h, \max } \forall s \\
0 \leq k_{s}^{d i s} \leq K_{s}^{d i s, \max } \forall s
\end{gathered}
$$

$$
\begin{aligned}
& 0 \leq k_{s}^{r e s} \leq K_{s}^{r e s, \max } \forall s \\
& u_{s, w, t, r}^{c h}+u_{s, w, t, r}^{d i s}+u_{s, w, t, r}^{i d l}=1 \quad \forall s, \forall w, \forall t, \forall r \\
& 0 \leq \bar{p}_{s, w, t, r}^{c h} \leq k_{s}^{c h} \forall s, \forall w, \forall t, \forall r \\
& 0 \leq \bar{p}_{s, w, t, r}^{c h} \leq u_{s, w, t, r}^{c h} \cdot M^{c h} \forall s, \forall w, \forall t, \forall r \\
& 0 \leq \bar{p}_{s, w, t, r}^{\text {dis }} \leq k_{s}^{\text {dis }} \forall s, \forall w, \forall t, \forall r \\
& 0 \leq \bar{p}_{s, w, t, r}^{d i s} \leq u_{s, w, t, r}^{d i s} \cdot M^{d i s} \forall s, \forall w, \forall t, \forall r \\
& o_{s, w, t, r}^{c h} \geq 0 \quad \forall s, \forall w, \forall t, \forall r \\
& o_{s, w, t, r}^{\text {dis }} \geq 0 \quad \forall s, \forall w, \forall t, \forall r \\
& 0 \leq e_{s, w, t, r} \leq k_{s}^{r e s} \forall s, \forall w, \forall t, \forall r \\
& e_{s, w, t, r}=E_{s}^{i n i}+\eta_{s} \cdot p_{s, w, t, r}^{c h}-p_{s, w, t, r}^{d i s} \quad \forall s, \forall w, t=1, \forall r \\
& e_{s, w, t, r}=e_{s, w,(t-1), r}+\eta_{s} \cdot p_{s, w, t, r}^{c h}-p_{s, w, t, r}^{d i s} \\
& \forall s, \forall w, \forall t>1, \forall r \\
& e_{s, w, t, r}=E_{s}^{i n i} \quad \forall s, \forall w, t=N_{t}, \forall r \\
& p_{s, w, t, r}^{c h}, p_{s, w, t, r}^{d i s}, \lambda_{w, t, r} \in \\
& \arg \text { minimize }\left\{\sum_{g=1}^{N_{g}} \beta_{g, w, t, r} \cdot p_{g, w, t, r}-\sum_{s=1}^{N_{s}} o_{s, w, t, r}^{c h} \cdot p_{s, w, t, r}^{c h}\right. \\
& +\sum_{s=1}^{N_{s}} o_{s, w, t, r}^{d i s} \cdot p_{s, w, t, r}^{d i s}-\sum_{d=1}^{N_{d}} U_{d, w, t} \cdot p_{d, w, t, r} \\
& \sum_{s=1}^{N_{s}}\left[p_{s, w, t, r}^{c h}-p_{s, w, t, r}^{d i s}\right]-\sum_{g=1}^{N_{g}} p_{g, w, t, r}+\sum_{d=1}^{N_{d}} p_{d, w, t, r}=0: \lambda_{w, t, r} \\
& 0 \leq p_{g, w, t, r} \leq P_{g}^{\max }: \mu_{g, w, t, r}^{\min }, \mu_{g, w, t, r}^{\max } ; \quad \forall g \\
& 0 \leq p_{d, w, t, r} \leq P_{d, w, t, r}^{\max }: \mu_{d, w, t, r}^{\min }, \mu_{d, w, t, r}^{\max } ; \forall d \\
& 0 \leq p_{s, w, t, r}^{c h} \leq \bar{p}_{s, w, t, r}^{c h}: \mu_{s, w, t, r}^{c h, \min }, \mu_{s, w, t, r}^{c h, \max } ; \forall s \\
& 0 \leq p_{s, w, t, r}^{d i s} \leq \bar{p}_{s, w, t, r}^{d i s}: \mu_{s, w, t, r}^{d i s, \min }, \mu_{s, w, t, r}^{\text {dis,max }} ; \forall s \\
& \} \forall w, \forall t, \forall r \text {. }
\end{aligned}
$$

The formulated problem is a stochastic bi-level model in which, two optimization problems interact. The upper-level problem, i.e., a.1 -a.17 models the planning and operation decisions of the storage facility from the owner's perspective. The lower-level problems, i.e., a.18)-a.23, represent the market-clearing process, for each hour of a week and for each scenario. The storage facility with fixed decisions competes in the market with other participants to buy/sell energy.

The objective function a.1 is composed of storage investment costs a.2 and expected weekly operation profit (a.3). Term a.2 includes investment costs associated with the charging component, the discharging component, and the reservoir capacity. We have defined charging and discharging capacities independently to make the model applicable to all technologies [20]. Note that for the sake of simplicity, the components' sizes are considered as continuous variables. Terms (a.3), one per scenario per week, imply the cost of charging and the profit from discharging. The storage facility makes strategic sizing decisions including $k_{s}^{c h}, k_{s}^{\text {dis }}$ and $k_{s}^{\text {res }}$. 
In addition to such strategic planning decisions, it is able to strategically make offering and bidding decisions in terms of quantity and price, i.e., $\bar{p}_{s, w, t, r}^{c h}, \bar{p}_{s, w, t, r}^{\text {dis }}, o_{s, w, t, r}^{c h}$, and $o_{s, w, t, r}^{d i s}$.

Constraints a.4 -a.6 bind the available capacity for each storage facility component. Three operation modes for the storage operation are considered in (a.7) consisting of discharging, charging, and idling, i.e., when the storage facility is operating in neither discharging nor charging. While it is possible to exclude this constraint in this particular formulation, we have decided to include it as it will be applicable and useful in future models where more than one revenue stream (e.g., arbitrage and ancillary services) are considered. Constraints a.8-a.9 and a.10-a.11 impose the upper and lower bounds for quantity bids and quantity offers regarding to charging and discharging modes, respectively. Constraints a.12 and a.13 enforce the non-negativity of storage facility bid and offer prices, respectively. Constraint a.14 refers to bounds for the storage energy reservoir. In this paper in line with [12], weekly horizons are considered for energy facility operation. Constraints a.15 and a.16 represent the storage facility state of charge for the first hour of a week and rest of hours, respectively. Constraint a.17) is to define the balance of stored energy at the end of each week. In this work, without loss of generality, we force the stored energy at the start and end of the weekly planning horizon to be the same.

The uncertainty associated with future market demand and other market participants' offers is reflected in the marketclearing problem through a set of scenarios, in line with [21]. We recognize that there are other methods available for modeling uncertainty such as robust optimization [4]. Exploring those alternatives is beyond the scope of the present work. To this end, the quantity bids of demands, i.e., $P_{d, w, t, r}^{\max }$ and the offering prices of generators, i.e., $\beta_{g, w, t, r}$ are assumed as uncertain parameters, and thus indexed by $r$. For each hour of the week and for each scenario, the market is cleared by a.18-a.23.

Note that several strategic market players may exist either in the generation- or demand-side. However, this paper solves the strategic storage sizing problem from an investor point of view. From its perspective, the market behavior of all other market participants, e.g., their investment and operational decisions, is fixed but generally uncertain.

For wind power plants, we have considered the uncertainty associated with net demand in the market, i.e., nondispatchable wind generation subtracted from the future load. Our future work is to model the interactions of several strategic players including strategic generators, wind power producers, and storage facilities, which leads to an equilibrium analysis.

The objective function of each lower-level problem is to minimize the negative of social welfare, i.e., a.18. The market operator clears the market based on submitted players' bids and offers. The market operation constraints are modeled in a.19-a.23. The dual variables pertaining to lower-level constraints are indicated following a colon within each one. Constraint a.19 represents the energy balance, whose dual variable provides the market-clearing price. Constraints a.20 and a.21 bind production and consumption levels, respectively. Constraints a.22 and a.23 refer to upper and lower bounds for the storage facility's charging and discharging components, respectively. To avoid an unmanageable large problem, we have ignored transmission network limits.

In conventional generation planning problems in the literature, load duration curves are typically used (e.g., [18] and [22]) because the level of energy consumption matters as opposed to the time sequence of energy consumption. However, in the case of energy storage, because charging provides fuel for discharging, the timing of consumption is as important as its level. Compared to an individual load or generator, energy storage could participate in the market as a load or as a generator and switches between charging, discharging, and idle modes regularly depending on market conditions. Also, buying and selling decisions are not entirely independent as the overall profit would depend on the sale price difference with respect to the purchase price. This dependency would make the decision-making problems of an energy storage facility more complex than a load or a generator. These fundamental differences are reflected in the proposed model, e.g., in a.15 and a.16 where those inter-temporal constraints link energy storage bidding and offering quantities in different hours.

While this problem could be directly solved for very small test cases using existing solvers, implementing this problem for a real-life test system will lead to extreme computational issues and eventual intractability. For example, considering Alberta's electric system with 300 market participants, the resulting matrix to be solved for this problem only for one week has more than 200,000 rows and columns for a deterministic case. Considering uncertainties and defining scenarios and extending the problem for a full year would make the problem much larger and harder to solve. Thus, we apply a decomposition algorithm for solving the formulated problem in the next section to mitigate the computational issues associated with the proposed problem for real-life case studies.

\section{The SOlution Algorithm}

We apply an algorithm based on Benders' decomposition to solve the formulated model. Benders' decomposition is suitable for solving this problem because (i), sizing variables, i.e., $k_{s}^{c h}, k_{s}^{\text {dis }}$ and $k_{s}^{r e s}$, are complicating variables [23] and (ii), the objective function a.1 is convex with respect to each of these variables. The well-functioning of Benders' decomposition in non-convex problems, e.g., a bi-level problem, is generally not guaranteed. However, there are several studies in the literature, e.g., [24]-[26], that efficiently applied this technique into "stochastic" non-convex problems providing that a sufficient number of scenarios is considered. The reason for this is that the objective function of the non-decomposed model convexifies with respect to the complicating variables as the number of scenarios and their diversity increases. The sizing decisions are considered as complicating variables because fixing these variables provides a decomposed model per scenario per week. Briefly, the algorithm is composed of the following steps. More details will follow.

- Step 1: Decompose the problem a.1 a.23 through fixing sizing decisions into a single master problem and several subproblems, one per scenario per week. 
- Step 2: In each Benders' iteration, solve the linear master problem and update the values for complicating variables. Fix the values of the complicating variables in the subproblems of that iteration. Each subproblem, one per scenario per week, is itself a bi-level problem. Recast each subproblem as a Mathematical Programs with Equilibrium Constraints (MPEC) [27]. Each MPEC provides the strategic operation decisions of the storage facility for the week and scenario under study.

- Step 3: Linearize the non-linear terms in the MPECs and convert each MPEC into a Mixed-Integer Linear Programming (MILP) problem.

- Step 4: Determine the continuous equivalent of each MILP subproblems and derive sensitivities.

- Step 5: Check the Benders' convergence criterion; if satisfied the optimal solution is obtained; otherwise, go to the next iteration and generate a new Benders' cut in the master problem based on sensitivities obtained in the previous iteration.

In Step 1, we decompose the problem into a master problem based on its investment term, i.e., a.2 and the operation term, i.e., a.3 of the objective function a.1. The resulting master problem is as follows:

$$
\begin{aligned}
& \text { Max. }-\alpha^{(m)}-g^{i n v,(m)} \\
& a .2, a .4-a .6 \\
& \alpha^{(m)} \geq \alpha^{\text {min }} \\
& \alpha^{(m)} \geq-\sum_{w=1}^{N_{w}} \sum_{r=1}^{N_{r}} \varphi_{r} . \widehat{g}_{w, r}^{o p r,(l)} \\
& +\sum_{w=1}^{N_{w}} \sum_{r=1}^{N_{r}} \varphi_{r} \cdot \sum_{s=1}^{N_{s}} \pi_{s, w, r}^{c h,(l)} \cdot\left(k_{s}^{c h,(m)}-\widehat{k}_{s}^{c h,(l)}\right) \\
& +\sum_{w=1}^{N_{w}} \sum_{r=1}^{N_{r}} \varphi_{r} \cdot \sum_{s=1}^{N_{s}} \pi_{s, w, r}^{d i s,(l)} \cdot\left(k_{s}^{d i s,(m)}-\widehat{k}_{s}^{d i s,(l)}\right) \\
& +\sum_{w=1}^{N_{w}} \sum_{r=1}^{N_{r}} \varphi_{r} \cdot \sum_{s=1}^{N_{s}} \pi_{s, w, r}^{r e s,(l)} \cdot\left(k_{s}^{r e s,(m)}-\widehat{k}_{s}^{r e s,(l)}\right) \\
& \forall l=\{1,2, \ldots, m-1\} .
\end{aligned}
$$

The goal of the master problem, which is a linear problem, is to determine the strategic size of the charging component, the discharging component, and the energy reservoir in each Benders' iteration, indexed by $m$. The parameters including superscript $l$ are fixed values obtained in the previous iterations. In particular, $\widehat{k}_{s}^{\text {ch, }(l)}, \widehat{k}_{s}^{\text {dis },(l)}$, and $\widehat{k}_{s}^{r e s,(l)}$ are sizing decisions obtained from the master problem in the previous iterations, while $\pi_{s, w, r}^{c h,(l)}, \pi_{s, w, r}^{d i s,(l)}$ and $\pi_{s, w, r}^{r e s,(l)}$ are sensitivities obtained from the subproblems in the previous iterations. Auxiliary variable $\alpha^{(m)}$ represents the minus expected operation profit of the storage facility. Constraint (b.2) is related to the sizing decisions in the original problem. Constraint b.3 imposes a lower bound on $\alpha^{(m)}$ to accelerate convergence. Constraints (b.4) are Benders' cuts. Note that in each iteration, a new cut is generated. The solution of master problem (b.1)-(b.4) updates the values of complicating variables, i.e., sizing decisions, to be included in the subproblems [28].
The resulting subproblem corresponding to week $w$ and scenario $r$ in iteration $m$ is as follows:

$\left\{\right.$ Max. $\quad g_{w, r}^{o p r,(m)}$

$k_{s}^{c h,(m)}=\widehat{k}_{s}^{c h,(m)}: \pi_{s, w, r}^{c h,(m)} \forall s$

$k_{s}^{d i s,(m)}=\widehat{k}_{s}^{d i s,(m)}: \pi_{s, w, r}^{d i s,(m)} \forall s$

$k_{s}^{r e s,(m)}=\widehat{k}_{s}^{r e s,(m)}: \pi_{s, w, r}^{r e s,(m)} \quad \forall s$

a.3, a.7 - a.23

(c.5) $\} \forall w, \forall r$.

Note that constraints (c.2)-(c.4) fix the values of complicating variables to those obtained from master problem (b.1)-(b.4). Also, the dual variables associated with constraints (c.2)-(c.4) provide sensitivities to generate Benders' cuts within master problem (b.1)- b.4 in the next iterations.

As for Step 2, the subproblem above is a bi-level problem by itself given that a.18-a.23 introduce another optimization problem within the subproblem. To solve this optimization problem, each lower-level problem a.18-a.23 is replaced by its Karush-Kuhn-Tucker (KKT) optimality conditions, which renders some complementarity conditions. Such an optimization problem is referred to an MPEC [29]. The interested reader can refer to [29] for further details on MPEC formulation.

The MPEC formulation includes non-linear terms due to the product of price and quantity variables and complementarity conditions. To convert each MPEC into an MILP, the strong duality condition [30] and disjunctive constraints [31] are used in Step 3.

In order for Benders' decomposition to provide optimal solutions, the subproblem must be continuous [23]. However, the MILP subproblems include binary variables introduced by storage operation's modes and disjunctive constraints. Step 4 is to overcome this challenge, in line with [25]. One can solve the mixed-integer linear version of the subproblem to obtain the optimal values of the following variables in iteration $m: u_{s, w, t, r}^{c h}, u_{s, w, t, r}^{d i s}, u_{s, w, t, r}^{i d l}, o_{s, w, t, r}^{c h}, o_{s, w, t, r}^{d i s}, \mu_{s, w, t, r}^{c h, m a x}$, and $\mu_{s, w, t, r}^{d i s, \max }$. Then, each subproblem is reformulated, one per scenario per week, as a continuous and linear problem.

The following convergence criterion is checked in Step 5 for each Benders' iteration:

$$
\left|\alpha^{(m)}+\sum_{w=1}^{N_{w}} \sum_{r=1}^{N_{r}} \varphi_{r} \cdot g_{w, r}^{o p r,(m)}\right| \leq \epsilon
$$

If the above holds, the optimal solution is achieved. If not, Benders' cut is generated and added to the master problem and another Benders' iteration is repeated. This is done by passing the new values of $\pi_{s, w, r}^{c h,(l)}, \pi_{s, w, r}^{d i s,(l)}$, and $\pi_{s, w, r}^{r e s,(l)}$ to (b.4). More details on Benders' decomposition method can be found in [23].

\section{NumericAl RESUlTS}

The numerical studies of this paper are divided into two sections, i.e., an illustrative example and a real-life case study. Both sections refer to cases related to the Alberta electricity market, however, different supply curves for rival generators are considered. In the cases included in the Illustrative 
TABLE I

PUMPED-STORAGE HYDRO FACILITY'S CHARACTERISTICS

\begin{tabular}{ccccc}
\hline $\begin{array}{c}M C_{s}^{c h} \\
(\$ / \mathrm{MWh})\end{array}$ & $\begin{array}{c}M C_{s}^{\text {dis }} \\
(\$ \mathrm{MWh})\end{array}$ & $\begin{array}{c}A C_{s}^{c h}=A C_{s}^{\text {dis }} \\
(\$ / \mathrm{MW}-\mathrm{yr})\end{array}$ & $\begin{array}{c}A C_{s}^{\text {res }} \\
(\$ / \mathrm{MWh}-\mathrm{yr})\end{array}$ & $\eta$ \\
\hline 0.9 & 0.6 & 54720 & 4,560 & 0.75 \\
\hline
\end{tabular}

Example, the rival generators offer based on their actual production costs. This assumption builds a basis to observe the impacts of the non-strategic or strategic behavior of the storage facility on its investment decisions. The non-strategic cases refer to a perfectly competitive market since all market players such as storage and rival producers offer truthfully based on their actual operation costs. However, the strategic cases refer to an imperfectly competitive market in which the storage facility behaves strategically. Unlike the cases in the Illustrative Example, we use the real data, i.e., the hourly supply curves of year 2013, as the rival generators' offers in Case Study.

\section{A. Illustrative Example}

Typical parameters, including operation and investment costs, for a pumped-storage hydro facility, are borrowed from [32] and [33]. The life of pumped-storage hydro facility is considered to be 50 years [32], and the capital cost is annualized using a Weighted Average Cost of Capital (WACC) of 9\% over this period [34]. The WACC is calculated base on the cost of equity and debt [35]. Thus, as long as the utility's revenue is higher than its amortized cost, it is a profitable investment. The amortized capital costs including fixed operation and maintenance costs and marginal operating costs are shown in Table I. The maximum available charging/discharging and energy reservoir of pumped-storage hydro are $1000 \mathrm{MW}$ and 20,000 MWh.

The marginal cost and capacity of existing types of generators in Alberta are borrowed from [36].

As given in Table II] five cases with different market conditions are considered. Cases A1, A2 and A3 refer to a perfect market condition while Cases A4 and A5 correspond to an imperfect market condition. Further details are provided below:

- Case A1 refers to a perfectly competitive market in which, all market players such as storage facility and rival generators offer based on their actual installed capacity and marginal cost to the market. In this case, the expansion and operational decisions are made centrally by a single entity, e.g., the market operator, and the obtained results are optimal for every player.

- Case A2 is similar to Case A1, however, the future load uncertainty is modeled by five load growth scenarios.

- Case A3 is similar to Case A2, however, the rival generators' supply curve uncertainty is also modeled by three scenarios. Given three rival generators' supply curve and five load growth scenarios, 15 scenarios are considered in this case.

- Unlike Cases A1 to A3, Case A4 refers to an imperfectly competitive market. In this case, the storage facility behaves strategically, while it perfectly knows the submitted offers of rival generators. This case is comparable with
TABLE III

ILLUSTRATIVE EXAMPLE: THE SIZING AND EXPECTED PROFIT OF STORAGE FACILITY ACROSS CASES A1 TO A5

\begin{tabular}{cccc}
\hline Case & $\begin{array}{c}k_{s}^{c h}=k_{s}^{\text {dis }} \\
(\mathrm{MW})\end{array}$ & $\begin{array}{c}k_{s}^{\text {res }} \\
(\mathrm{MWh})\end{array}$ & $\begin{array}{c}\text { Change in the storage } \\
\text { facility's expected profit } \\
\text { compared to that in Base } \\
\text { Case, i.e., Case A1 (\%) }\end{array}$ \\
\hline Case A1 (Base case) & 661 & 6522 & - \\
Case A2 & 753 & 7755 & +21.88 \\
Case A3 & 764 & 7794 & +22.29 \\
Case A4 & 861 & 4061 & +42.18 \\
Case A5 & 882 & 4147 & +44.36 \\
\hline
\end{tabular}

Case A2 because of the same source of uncertainty and scenarios considered.

- Case A5 is similar to Case A4 while considering the uncertainty in submitted offers of rival generators. This case is comparable with Case A3 because of the same sources of uncertainty and scenarios considered.

The results for these five cases are given in Table III Based on the results, a number of observations are made, as follows. A comparatively larger storage facility is determined in Case A2 compared to that in Case A1. The reason is that more investment on the storage facility in Case A2 compared to Case A1 reduces the future operation cost under load growth uncertainty. This larger capacity leads to an increase in the storage facility's expected profit. Compared to Case A2, the storage facility's size and expected profit are slightly increased in Case A3 since there is more uncertainty in this case. In Cases A4 and A5 referring to the imperfect market, the storage facility's expected profit is significantly increased with respect to that in perfect market cases, i.e., Cases A1 to A3. These results highlight the impacts of storage facility's behavior on its planning decisions and its profit. Another interesting observation is that in the imperfect market cases, i.e., Cases A4 and A5, the strategic storage facility decides to build a comparatively larger charging/discharging device, but a comparatively smaller energy reservoir. The reason for this is that the storage facility is dispatched in more hours within the perfect market cases compared to Cases A4 and A5. For example, in Case A2, the storage facility operates in the discharging mode in $28 \%$ hours of a year, compared to $17 \%$ in Case A4. Thus, the storage facility's energy reservoir is smaller in Cases A4 and A5 compared to Cases A1 to A3. On the other hand, the strategic storage charges/discharges more energy in its operating hours to maximize its profit. Thus, a larger charging/discharging component is determined. Similar to the perfect market cases, the strategic storage facility gains higher profit if more uncertainties are considered. However, this depends on the evaluated scenarios.

\section{B. Case Study}

We apply the proposed model and the solution methodology considering the real-life data from Alberta's electricity market to decide the strategic sizing of a pumped-storage hydro facility in Alberta.

Alberta electricity market is an energy-only wholesale market [37]. We consider Alberta electricity market as an imperfect market since the suppliers in this market are not forced to submit their actual marginal costs as offer prices [38]. In other words, they are allowed to submit their capacity 
TABLE II

ILlustrative EXAMPLE: MARKeT CONDITIONS ACROSS CASES A1 TO A5

\begin{tabular}{|c|c|c|c|c|c|}
\hline \multirow[t]{2}{*}{ Case } & \multirow{2}{*}{$\begin{array}{l}\text { Behavior of } \\
\text { storage facility }\end{array}$} & \multirow{2}{*}{$\begin{array}{l}\text { Model } \\
\text { needed }\end{array}$} & \multicolumn{2}{|c|}{ Source of uncertainty } & \multirow{2}{*}{ Description } \\
\hline & & & Load growth & Generators' offer prices & \\
\hline Case A1 & & & No & No & $\begin{array}{l}\text { These three cases refer to a perfect market, in which the market } \\
\text { operator centrally makes all sizing and operational decisions. } \\
\text { These decisions are optimal for every player. }\end{array}$ \\
\hline Case A3 & & & Yes & Yes & \\
\hline $\begin{array}{l}\text { Case A4 } \\
\text { Case A5 }\end{array}$ & Strategic & Bi-level Programming & $\begin{array}{l}\text { Yes } \\
\text { Yes }\end{array}$ & $\begin{array}{l}\text { No } \\
\text { Yes }\end{array}$ & $\begin{array}{l}\text { These two cases refer to an imperfect market, in which the } \\
\text { storage facility behaves strategically, i.e., it offers/bids at quan- } \\
\text { tities and prices that might be different than its actual installed } \\
\text { capacity and marginal costs. } \\
\text { All conventional generators offer their actual installed capacity } \\
\text { at actual marginal costs. The storage facility is the leader } \\
\text { while market clearing under different operating conditions are } \\
\text { followers. }\end{array}$ \\
\hline
\end{tabular}

at any price between $\$ 0 / \mathrm{MWh}$ and $\$ 999.99 / \mathrm{MWh}$, i.e., the market price cap [37]. An analysis on Alberta market-clearing outcomes from 2008 to 2014 has been carried out in [38], which shows exercising significant market power during this period of study.

The interest in integrating energy storage facilities into Alberta's market has grown considerably over the past few years [39]. Reasons include the funding provided by the Climate Change and Emissions Management Corporation (CCEMC) [40] and the potential benefits of energy storage in facilitating higher penetration of wind power into the system [41]. In 2014, Alberta Innovates-Energy and Environment Solutions (AI-EES) announced \$2 million to assist developing the most promising energy storage technologies for Alberta [42]. A number of energy storage interconnection applications, including one for pumped-storage hydro and one for a compressed air energy storage, are filed with the Alberta Electric System Operator (AESO) [39]. The value proposition of these projects is mainly around energy arbitrage through internal and inter-market transactions considering the high volatility and sometimes significant price differentials in Alberta's market. In the case study here, we consider the same storage facility characteristics as explained in Illustrative Example.

In line with [18] and [25], this study is performed for a single target year, i.e., static investment analysis. To represent the offering strategies of other market participants, we use the offering data for more than 300 suppliers in Alberta's market for year 2013 as the base scenario [43]. Based on actual market data, we build market supply curves for every single hour of the year. The load is inelastic and is considered as one single bid at Alberta market's price cap, which is a realistic assumption in this market.

We generate scenarios in order to include the uncertainties associated with future market net load and other market participants' offering strategies. Net load refers to electrical demand minus the non-dispatchable supply. In many markets, non-dispatchable units do not participate in the market and as such, their expected supply is deducted from the pure load to calculate net load. We characterize each scenario by two factors, i.e., a net load growth/drop factor and an upward/downward shift in offer prices of other market participants. We recognize that other sources of uncertainties may exist in the market (e.g., market structural changes in the future, generation mix evolution, and environmental policies).
However, including such sources of uncertainty in a single test case makes the problem intractable and is left to be explored in the authors' future work.

We have applied the proposed methodologies for seven case studies, i.e., Cases B1 to B7. The cases are generated based on year 2013 data. In year 2013, non-dispatchable units, including wind power producers did not participate in the market and thus, the market net load was the basis of clearing the market. In three of the case studies, namely Cases B1, B2 and B3, we consider an increase in net load, i.e., more growth in consumption than in adding renewables. Alberta has had a net load growth over the past few years while wind development in the province was picking up. With a growth in net load, it is reasonable to assume an upward movement in supply offers in response to increased demand in the market. Hence, we have considered an upward movement between $0 \%$ to $20 \%$ for these cases. Note that the higher load or higher offer prices may motivate not only the storage investor but also the rival generators to expand their current capacities. In this case, the rival generators' investment decisions can be considered as an additional source of uncertainty. For simplicity, this additional uncertainty is not considered in this paper, however, it is straightforward to model it by additional scenarios.

In Case B4, we alter the base data slightly to model business as usual. The slight changes are to generate scenarios and enable the solution method to work. In other words, Case B4 is to see if we were to build the facility based on year 2013 data, what the solutions would have been.

In the three other cases, i.e., Cases B5 to B7, we consider a drop in future net load in the system- see Table IV] for details. A drop in net load is something possible given the large-scale integration of wind and solar in power systems. If the net load in the market has dropped, it is reasonable to assume that it could put a downward pressure on generators offers. Thus, in Cases B5 to B7, we consider alternative values for such downward pressure, between $0 \%$ to $20 \%$.

It is worth mentioning that only one source of uncertainty, either load growth scenarios or offer price scenarios of rival generators, is changed over these cases, except Case B4. This allows us to gain insight into impacts of each source of uncertainty on results. For example, in Case B2 compared to Case B1, rival generators' offer prices are identical while considering a comparatively lower load growth. This way, we observe the impacts of load growth uncertainty on the results. 
Similarly, in Case B3 compared to Case B2, identical load growth scenarios are considered while rival generators offer at comparatively lower prices. This allows concluding the impacts of rival generators' offer prices on the results. Similar distinctions can be made for Cases B5 to B7.

The numerical results of strategic sizing along with the facility's expected profit, the mean price impact of the facility's operation during charging and discharging hours, program run time and the number of Benders' iteration for each case study are presented in Table IV. Price impact here refers to how actions of the facility impact hourly market prices.

To investigate the impact of higher system net load on sizing decisions, let compare Case B2 to Case B1 where the net load has gone up from one to another. The resulting strategic size has also gone up from $577 \mathrm{MW}(6115 \mathrm{MWh})$ to $662 \mathrm{MW}$ (9853 MWh). This is reasonable because, with the same supply curves, higher demand generally leads to higher market prices, improving the economics of energy storage arbitrage operation and justifying higher capacities. The same observation is true for Case B7 compared to Case B6.

Higher offer prices in the market would have a similar impact on strategic sizing. Comparing Case B3 to Case B2, with the same net load scenarios, higher offer prices have led to higher sizes. It is reasonable to think that higher offer prices would generally lead to higher market prices and improve the facility's economy even at higher sizes. The same observation is true for Case B6 compared to Case B5.

Note also from Table IV that the expected profit has grown with higher size values. This indicates that despite the higher downward pressure that the facility's size puts on market prices during the discharging hours, its profit grows. This reason lies in the fact that the profit is a function of quantities traded and the market prices.

From Table IV and for all cases, the actions of the storage facility has a significant price impact. However, the mean price impact during charging hours is lower than that for discharging hours. This is not an unexpected finding because charging typically occurs during low-demand hours where the supply curves are flatter. In opposite, discharging typically occurs during high-price hours where the supply curve is very steep and small supply movements have a higher impact on prices.

For an arbitrary scenario in Case B4, the bidding/offering decisions of the storage facility in two typical hours, referred to here by charging hour and discharging hour, are presented in Figs. 1 and 2 respectively. For the charging hour, the storage facility bids to buy $257 \mathrm{MW}$ at $\$ 22.15 / \mathrm{MWh}$ - see Fig. 1 . This bid along with that of the inelastic market demand makes the demand curve for this particular hour. Because of the increased demand, the market-clearing price would increase to $\$ 22.15 / \mathrm{MWh}$ from $\$ 19.22 / \mathrm{MWh}$, compared to when there is no storage bid. Note that a number of new supply offers are also accepted for this hour to cover the storage charging demand. For a typical discharging hour, as per Fig. 2, the storage facility offers to sell $224 \mathrm{MW}$ at $\$ 31.6 / \mathrm{MWh}$. This offer would be integrated into the supply curve, as in Fig. 2. and shifts the curve to the right, which leads to the lower market-clearing price of $\$ 31.6 / \mathrm{MWh}$ down from $\$ 50 / \mathrm{MWh}$. Observe from Fig. 2 that the storage facility could submit a

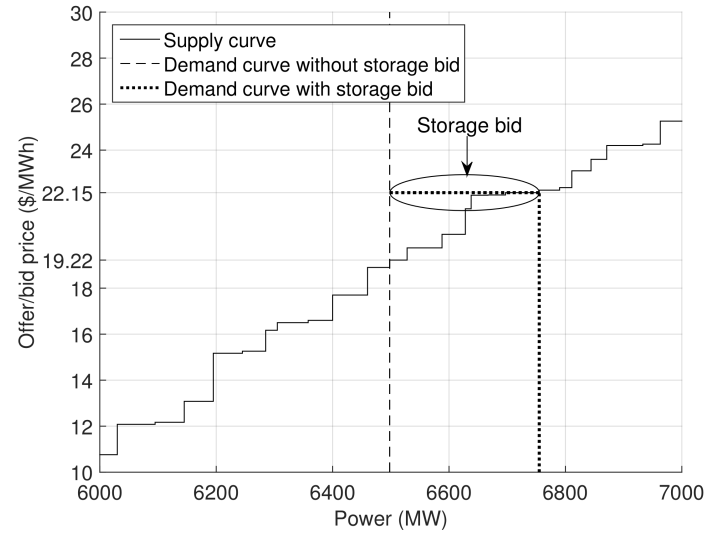

Fig. 1. Case Study: the supply offers, demand curves and storage offer at charging mode in a typical hour and for a particular scenario in Case B4

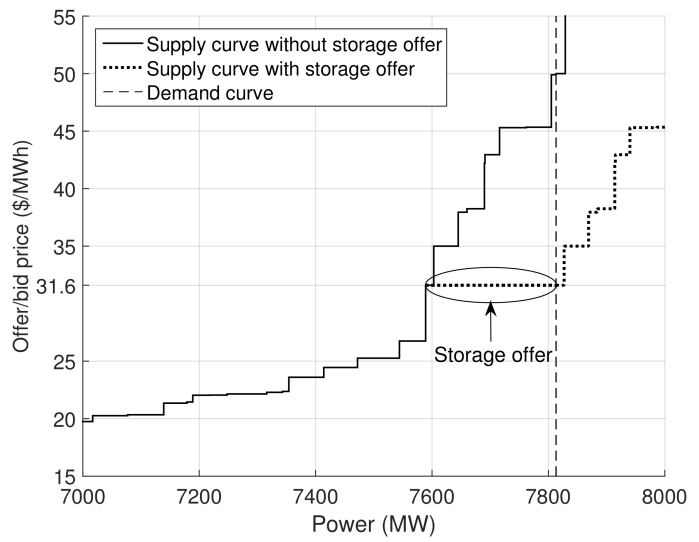

Fig. 2. Case Study: the supply offers, demand curves and storage offer at discharging mode in a typical hour and for a particular scenario in Case B4

comparatively higher quantity offer (e.g., $260 \mathrm{MW}$ ), but at the cost of clearing the market at a comparatively lower price, which results in a lower profit for the storage facility. Thus, the most profitable strategy for the storage facility is to submit an offer to sell $224 \mathrm{MW}$ at $\$ 31.6 / \mathrm{MWh}$ in this typical hour, which is the best combination of quantity and price offer for that player. Note that since physical withholding is not allowed in Alberta's market [44], the storage facility offers the rest of its production capacity at offer price cap, i.e., $\$ 999.99 / \mathrm{MWh}$ 45..

To verify the optimality of the obtained results, we performed an ex-post numerical analysis by varying the size of the storage reservoir for different charging/discharging capacities for Case B7, and the results are presented in Fig. 3. As illustrated in this figure, the value of the objective function, i.e., the expected profit of the storage facility, projected on the subspace of the complicating variables has a convex envelope. This validates the successful implementation of Benders' decomposition. As the figure demonstrates, the maximum expected profit is achieved at the optimal values determined by the model, as presented in Table IV

Comparing Case B4 to other cases, there is a little uncertainty in this case. Thus, one can consider this case as "deterministic" case. It is clear from the resulting sizing values for this case, compared to other cases, that inclusion of plausible uncertainties in future market development has a 
TABLE IV

CASE STUdy: The Results

\begin{tabular}{|c|c|c|c|c|c|c|c|c|c|}
\hline Case & $\begin{array}{l}\text { Load } \\
\text { change } \\
(\%)\end{array}$ & $\begin{array}{l}\text { Gen. offers } \\
\text { change } \\
(\%)\end{array}$ & $\begin{array}{c}k_{s}^{c h}=k_{s}^{d i s} \\
(\mathrm{MW})\end{array}$ & $\begin{array}{c}k_{s}^{r e s} \\
\text { (MWh) }\end{array}$ & $\begin{array}{l}\text { Expected } \\
\text { profit } \\
(\mathrm{M} \$)\end{array}$ & $\begin{array}{l}\text { Mean price im- } \\
\text { pact during cha- } \\
\text { rging hours }(\%)\end{array}$ & $\begin{array}{l}\text { Mean price im- } \\
\text { pact during discha- } \\
\text { rging hours }(\%)\end{array}$ & $\begin{array}{l}\text { Running } \\
\text { time } \\
\text { (h) }\end{array}$ & $\begin{array}{l}\text { Benders' } \\
\text { iteration } \\
\text { numbers }\end{array}$ \\
\hline Case B1 & $+3,+4,+5$ & $0,+5,+10,+15,+20$ & 662 & 9853 & 28.31 & +19.71 & -22.30 & $5: 45$ & 8 \\
\hline Case B2 & $+1,+2,+3$ & $0,+5,+10,+15,+20$ & 577 & 6115 & 19.41 & +14.98 & -19.83 & $5: 36$ & 8 \\
\hline Case B3 & $+1,+2,+3$ & $0,+2.5,+5,+7.5,+10$ & 457 & 5627 & 14.24 & +13.99 & -18.41 & $5: 30$ & 8 \\
\hline Case B4 & $-0.01,0,+0.01$ & $-0.02,-0.01,0,+0.01,+0.02$ & 328 & 3177 & 8.04 & +10.21 & -15.96 & 4.12 & 8 \\
\hline Case B5 & $0,-1,-2$ & $0,-2.5,-5,-7.5,-10$ & 233 & 2005 & 4.64 & +8.51 & -14.04 & $3: 46$ & 9 \\
\hline Case B6 & $0,-1,-2$ & $0,-5,-10,-15,-20$ & 141 & 1167 & 2.08 & +7.22 & -10.94 & $3: 54$ & 8 \\
\hline Case B7 & $-1,-2,-3$ & $0,-5,-10,-15,-20$ & 85 & 830 & 0.76 & +4.33 & -8.74 & $3: 21$ & 7 \\
\hline
\end{tabular}

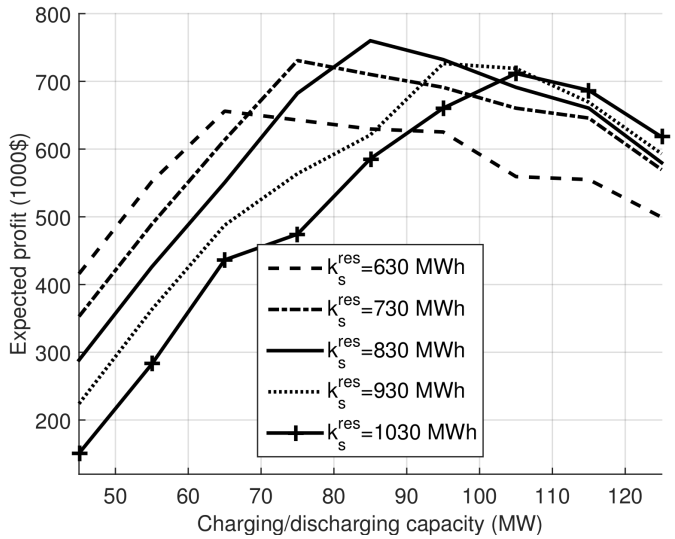

Fig. 3. Case Study: the expected profit for various storage components' sizes in Case B7

direct and sometimes significant impact on sizing decisions. Thus, similar to any other long-term investment planning, the problem of storage sizing is highly dependent upon how close the generated scenarios would resemble market conditions and the assumptions around how the facility would play in the market. Hence, one needs to gather all available information to produce scenarios that are as educated as possible, and make modeling assumptions with care. One other point is that in the planning model presented in this paper, the only source of revenue is coming from energy arbitrage. Including other sources of revenue would also impact the sizing and operation decisions, and add to the complexity and uncertainty of this planning problem.

We solved the formulated problems using CPLEX solver under General Algebraic Modeling System (GAMS) [46] on a Core i7 CPU and 32GB RAM computer. From Table IV] note that despite the relatively low number of Benders' iterations, the run time could be as high as six hours. This is because the number of subproblems in each iteration is large, which is driven by the number of weeks of study and scenarios.

\section{CONCLUSIONS}

This paper proposes a bi-level model for strategic sizing of a storage facility considering market uncertainties. The upper-level problem models the planning and operation decisions of the storage facility. Accordingly, the strategic size of storage components, including the charging device, the discharging device, and the energy reservoir are determined in the upper-level. In addition, the operation decisions of the storage facility, i.e., its bids/offers in terms of both price and quantity, are strategically made in the upper-level problem. The market-clearing process under different operating conditions is modeled in the lower-level problems, which is to maximize the social welfare. Uncertainties associated with rival generators' offering strategies and future net load are considered through a number of plausible scenarios. Due to the computational complexity of the proposed model, implementing this problem for a real-life test system may lead to extreme computation burden and eventual intractability. To make the proposed model computationally tractable, an efficient solution technique based on Benders' decomposition is utilized, rendering a master problem and a number of subproblems, one per scenario per week. This makes the proposed model computationally more manageable.

The proposed model was applied to obtain the strategic sizes of a pumped-storage hydro facility's components based on real data from Alberta's electricity market. The actual supply and demand curves considering more than 300 generators for each hour of a year were used to generate future scenarios for the uncertainties in the model. We also investigated the sizing problem under the assumptions of perfect competition and the facility being a price-taker. The results showed that the sizing values are highly dependent upon the assumptions and the employed scenarios and one needs to approach the sizing problem with care. The future work of the authors includes investigating the impacts of adding other sources of uncertainty, including other sources of revenue for the facility (e.g., ancillary services or real-time markets) and considering the impact of the joint operation of storage facilities with wind/solar farms on optimal storage sizing.

\section{REFERENCES}

[1] P. Hockenos, "Energy storage market outlook 2015," February 2015. [Online]. Available: http://www.renewableenergyworld.com/rea/news/ article/2015/02/energy-storage-market-outlook-2015

[2] J. Eyer and G. Corey, "Energy storage for the electricity grid: Benefits and market potential assessment guide," Technical Report SAND20100815, Sandia National Laboratories, Feb. 2010.

[3] J. Mitra, "Reliability-based sizing of backup storage," IEEE Transactions on Power Systems, vol. 25, no. 2, pp. 1198-1199, May 2010.

[4] R. A. Jabr, I. Dzafic, and B. C. Pal, "Robust optimization of storage investment on transmission networks," IEEE Transactions on Power Systems, vol. 30, no. 1, pp. 531-539, Jan. 2015.

[5] H. Pandzic, Y. Wang, T. Qiu, Y. Dvorkin, and D. Kirschen, "Nearoptimal method for siting and sizing of distributed storage in a transmission network," IEEE Transactions on Power Systems, vol. 30, no. 5, pp. 2288-2300, Sep. 2015.

[6] S. Chen, H. Gooi, and M. Wang, "Sizing of energy storage for microgrids," IEEE Transactions on Smart Grid, vol. 3, no. 1, pp. 142-151, Mar. 2012.

[7] S. Wen, H. Lan, Q. Fu, D. Yu, and L. Zhang, "Economic allocation for energy storage system considering wind power distribution," IEEE Transactions on Power Systems, vol. 30, no. 2, pp. 644-652, Mar. 2015.

[8] H. Oh, "Optimal planning to include storage devices in power systems," IEEE Transactions on Power Systems, vol. 26, no. 3, pp. 1118-1128, Aug. 2011. 
[9] A. Lamont, "Assessing the economic value and optimal structure of large-scale electricity storage," IEEE Transactions on Power Systems, vol. 28, no. 2, pp. 911-921, May 2013.

[10] M. Dicorato, G. Forte, M. Pisani, and M. Trovato, "Planning and operating combined wind-storage system in electricity market," IEEE Transactions on Sustainable Energy, vol. 3, no. 2, pp. 209-217, Apr. 2012.

[11] K. Bradbury, L. Pratson, and D. Patino-Echeverri, "Economic viability of energy storage systems based on price arbitrage potential in real-time U.S. electricity markets," Applied Energy, vol. 114, pp. 512 - 519, Feb. 2014.

[12] R. Sioshansi, P. Denholm, and T. Jenkin, "A comparative analysis of the value of pure and hybrid electricity storage," Energy Economics, vol. 33, no. 1 , pp. $56-66,2011$

[13] E. Fertig and J. Apt, "Economics of compressed air energy storage to integrate wind power: A case study in ERCOT," Energy Policy, vol. 39, no. 5, pp. 2330 - 2342, May 2011.

[14] A. S. A. Awad, J. D. Fuller, T. H. M. EL-Fouly, and M. M. A. Salama, "Impact of energy storage systems on electricity market equilibrium," IEEE Transactions on Sustainable Energy, vol. 5, no. 3, pp. 875-885, Jul. 2014.

[15] B. Hobbs, C. Metzler, and J.-S. Pang, "Strategic gaming analysis for electric power systems: an MPEC approach," IEEE Transactions on Power Systems, vol. 15, no. 2, pp. 638-645, May 2000.

[16] Rocky Mountain Power (RMP) Inc. website. [Online]. Available: http://rockymountainpower.ca/

[17] H. Zareipour, A. Janjani, H. Leung, A. Motamedi, and A. Schellenberg, "Classification of future electricity market prices," IEEE Transactions on Power Systems, vol. 26, no. 1, pp. 165-173, Feb. 2011.

[18] F. H. Murphy and Y. Smeers, "Generation capacity expansion in imperfectly competitive restructured electricity markets," Operations Research, vol. 53, no. 4, pp. 646-661, Jul. 2005.

[19] L. Baringo and A. J. Conejo, "Strategic wind power investment," IEEE Transactions on Power Systems, vol. 29, no. 3, pp. 1250-1260, May 2014.

[20] S. Eckroad, "Handbook of energy storage for transmission or distribution applications," Electric Power Research Institute Report, California, USA, 2002

[21] A. J. Conejo, M. Carrion, and J. M. Morales, Decision Making Under Uncertainty in Electricity Markets. International Series in Operations Research \& Management Science. New York, NY, USA: Springer, 2010.

[22] S. J. Kazempour, A. J. Conejo, and C. Ruiz, "Strategic generation investment using a complementarity approach," IEEE Transactions on Power Systems, vol. 26, no. 2, pp. 940-948, May 2011.

[23] J. Benders, "Partitioning procedures for solving mixed variable programming problems," Numerische Mathematik, vol. 4, pp. 238-252, 1962.

[24] L. Baringo and A. Conejo, "Wind power investment: A Benders' decomposition approach," IEEE Transactions on Power Systems, vol. 27, no. 1, pp. 433-441, Feb. 2012.

[25] S. J. Kazempour and A. J. Conejo, "Strategic generation investment under uncertainty via Benders' decomposition," IEEE Transactions on Power Systems, vol. 27, no. 1, pp. 424-432, Feb. 2012.

[26] A. J. C. A. Nasri, S. J. Kazempour and M. Ghandhari, "Networkconstrained AC unit commitment under uncertainty: A benders' decomposition approach," IEEE Transactions on Power Systems, vol. 31, no. 1, pp. 412-422, Jan. 2016

[27] B. Hobbs, C. Metzler, and J. Pang, "Strategic gaming analysis for electric power systems: an mpec approach," IEEE Transactions on Power Systems, vol. 15, no. 2, pp. 638-645, May 2000.

[28] E. Nasrolahpour and H. Ghasemi, "Congestion management through rotor stress controlled optimal transmission switching," IET Generation, Transmission \& Distribution, vol. 9, no. 12, pp. 1369-1376, Feb. 2015.

[29] S. A. Gabriel, A. J. Conejo, J. D. Fuller, B. F. Hobbs, and C. Ruiz, Complementarity Modeling in Energy Markets. International Series in Operations Research \& Management Science. New York, NY, USA Springer, 2013.

[30] C. Ruiz and A. J. Conejo, "Pool strategy of a producer with endogenous formation of locational marginal prices," IEEE Transactions on Power Systems, vol. 24, no. 4, pp. 1855-1866, Nov. 2009.

[31] J. Fortuny-Amat and B. McCarl, "A representation and economic interpretation of a two-level programming problem," The Journal of the Operational Research Society, vol. 32, no. 9, pp. 783-792, Sep. 1981.

[32] H. Zhao, Q. Wu, S. Hu, H. Xu, and C. N. Rasmussen, "Review of energy storage system for wind power integration support," Applied Energy, vol. 137, pp. $545-553$, Jan. 2015
[33] BC Hydro, "Pumped storage at Mica generating station, preliminary cost estimate," 2010. [Online]. Available: http://www.bchydro.com/content/ dam/hydro/medialib/internet/documents/planning_regulatory/iep_ltap/ ror/appx_10b_pumped_storage_mica_preliminary_cost_estimate.pdf

[34] Alberta Electric System Operator (AESO), "AESO 2012 long-term outlook," 2012.

[35] Williamson, O. E., "Transaction cost economics," Elsevier Science Publishers B. V., 1989.

[36] Alberta Electric System Operator (AESO), "2014 long-term outlook data file," 2014. [Online]. Available: www.aeso.ca/downloads/2014_ Long-term_Outlook_Data_File.xlsx

[37] Alberta Electric System Operator (AESO) website. [Online]. Available: http://ets.aeso.ca/

[38] D. P. Brown and D. E. H. Olmstead, "Measuring market power and the efficiency of albertas restructured electricity market: An energy-only market design,” Working Paper, no. 2015-14, Sep. 2015. [Online]. Available: http://www.ualberta.ca/ econwps/2015/wp2015-14.pdf

[39] Alberta Electric System Operator (AESO), "Energy storage integration," 2014. [Online]. Available: http://www.aeso.ca/downloads/Energy_ Storage_Integration_Discussion_Paper.pdf

[40] Climate Changes and Emissions Management (CCEMC) Corporation, "Call for expressions of interest renewable energy," 2012. [Online]. Available: http://ccemc.ca/_uploads/ 2012-Renewable-Energy-EOI-Guide-and-Instructions-Final1.pdf

[41] Alberta Electric System Operator (AESO), "Energy storage initiative issue identification," 2013. [Online]. Available: http://www.aeso.ca/ downloads/Formatted_ES_IS_Paper_Final_20130613.pdf

[42] Alberta Innovates- Energy and Environment Solutions (AI-EES), "\$2 million call for proposals- next generation renewable energy storage technologies," 2014. [Online]. Available: http://albertainnovates. $\mathrm{ca} /$ media/22192/ai-ees_energy_storage_2millionfunding.pdf

[43] Alberta Electric System Operator (AESO). [Online]. Available: http://ets.aeso.ca/

[44] Alberta Market Surveillance Administrator (MSA), "Offer behavior guidelines for Alberta's wholesale electricity market," Jan. 2011.

[45] H. Z. J. MacCormack, A. Hollis and W. Rosehart, "The large-scale integration of wind generation: Impacts on price, reliability and dispatchable conventional suppliers," Energy Policy, vol. 38, no. 7, pp. 3837-3846, Jul. 2010.

[46] GAMS platform, "General Algebraic Modeling System (GAMS)." [Online]. Available: http://www.gams.com/

Ehsan Nasrolahpour (S'14) received the B.Sc. degree from the Shahid Chamran University of Ahvaz, Ahvaz, Iran, in 2010, the M.Sc. degree from University of Tehran, Tehran, Iran, in 2013. He is currently pursuing his Ph.D. at University of Calgary, Calgary, AB, Canada. His research interests include power systems, electricity markets, and operations research.

S. Jalal Kazempour (S'08-M'14) received the B.Sc. degree from the University of Tabriz, Tabriz, Iran, in 2006, the M.Sc. degree from Tarbiat Modares University, Tehran, Iran, in 2009, and the Ph.D. degree from the University of Castilla-La Mancha, Ciudad Real, Spain, in 2013, all in electrical engineering. In 2014, he was a postdoctoral fellow at the Whiting School of Engineering, Johns Hopkins University, Baltimore, MD, USA. He is currently a postdoctoral fellow at the Department of Electrical Engineering, Technical University of Denmark, Kgs. Lyngby, Denmark. His research interests include power systems, electricity markets, optimization, and its applications to energy systems.

Hamidreza Zareipour (S'03-M'07-SM'09) received the Ph.D. degree in electrical engineering from the University of Waterloo, Waterloo, ON, Canada, in 2006. He is currently a full Professor with the Department of Electrical and Computer Engineering, University of Calgary, Calgary, AB, Canada. His research focuses on economics, planning, and management of power and energy systems in a deregulated electricity market environment. 
William D. Rosehart (SM'05) received the B.Sc, M.Sc., and Ph.D. degrees in electrical engineering from the University of Waterloo, Waterloo, ON, Canada. Currently, he is the Dean of Schulich School of Engineering at the University of Calgary, Calgary, AB, Canada. His main research interests are in the areas of numerical optimization techniques, power system stability, and modeling power systems in a deregulated environment. 